\title{
SEASONAL POLLUTANT REMOVAL BY LACTUCA SATIVA, MEDICAGO SATIVA AND PHRAGMITES AUSTRALIS IN CONSTRUCTED WETLANDS
}

\author{
Aminsharei, F. ${ }^{1}-$ Borghei, S. M. ${ }^{2 *}-$ ArJomandi, R. ${ }^{1}-$ NOURI, J. ${ }^{1}-$ PendashteH, A. ${ }^{3}$ \\ ${ }^{I}$ Department of Environmental Management, Science and Research Branch, \\ Islamic Azad University, Tehran, Iran \\ ${ }^{2}$ Biochemical and Bioenvironmental Research Center, \\ Sharif University of Technology, Tehran, Iran \\ ${ }^{3}$ The Caspian Sea Basin Research Center \\ University of Gilan, Rasht, Iran \\ *Corresponding author \\ e-mail: mborghei22@gmail.com \\ (Received 13 ${ }^{\text {th }}$ Dec 2016; accepted 24 ${ }^{\text {th }}$ Mar 2017)
}

\begin{abstract}
The main objective of this study was to compare the removal efficiency of nutrients using Lactuca sativa, Medicago sativa and Phragmites australis in subsurface flow constructed wetlands with horizontal flow. In order to test water quality, fabricated reactors designed and the plants cultivated in the soil while their root were inside the wastewater. A long time study carried out from spring till end of autumn (9 months) in order to evaluate the difference in removal rate based on the seasonal changes. The highest removal rate was during summer which followed by spring and autumn. Thus, the effect of plants on the removal efficiency of organic matter (COD, BOD), TSS and nutrient (P and TN) appeared to be dependent on the seasonal growth. Phragmites australis the most sensitive species in order the removal of nutrient from wastewater.
\end{abstract}

Keywords: subsurface flow constructed wetland, nutrient removal, wastewater treatment; Lactuca sativa, Medicago sativa, Phragmites australis

\section{Introduction}

Today, constructed wetlands are recognized as a reliable wastewater treatment technology and they represent a suitable solution for the treatment of many types of wastewater. Constructed wetlands have been used extensively across the world for treating wastewater due to its low cost and efficiency in removal of pollutants (Vymazal, 2010). Wastewater treatment in wetland occurred by a process named phytoremediation that is a moderately late innovation and is seen as practical, proficient, novel, eco-friendly technology, still in its initial improvement stages and full scale applications are still constrained (Rezania et al., 2015). Wide range of wastewaters such as municipal, industrial, agricultural, and storm water can be remediated in constructed wetland (CWs) (Pedescoll et al., 2015; Qasaimeh et al., 2015). In addition, CWs is a flexible and effective method for treating and reusing wastewater with less greenhouse gas emission (Chen et al., 2011).

Generally, the major functions of plants in CWs is to create conditions suitable for removal of pollutants and the direct role of plants is limited to uptake of nutrients and heavy metals (Marchand et al., 2010). Brisson and Chazarenc (2009) showed that some environmental factors like temperature, $\mathrm{pH}$, solar radiation and water salinity can influence plant growth and its performance in phytoremediation. The importance of 
these parameters are related to size, weight and growth rate of aquatic plants (Lissy and Madhu, 2010).

Based on Tanner (2001), wetland plants provide only small improvements in biological oxygen demand (BOD), chemical oxygen demand (COD) and faecal bacterial indicator removal but provide measurable enhancement of nutrient removal, mainly by promoting transformations to gaseous forms and sequestration in accumulating organic matter. As extensively reviewed by Engloner (Engloner, 2009), considering the worldwide distribution, Phragmites dominated wetlands may have a considerable effect on climate change. Because of this issue, the significance of common reed in scientific research will be on-going in the future studies. Phragmites australis is the most often used plant in CWs although a large diversity of species can be used and the genus Typha and Scirpus are commonly used (Vymazal, 2013). As described by Engloner (2004), water availability is an important factor in shoot which is longer in wetter than drier habitats (with maximum water depths $40-0$ and $-30 \mathrm{~cm}$, respectively).

In the Czech Republic, horizontal subsurface flow CWs are mostly planted with Phragmites australis (Common reed) or Phalaris arundinacea (Reed canarygrass) or with a combination of these two species. Some factors like: (1) excellent germination from the seeds, (2) easy planting, (3) fast growth, creating full cover of the surface during the first growing season if planted in spring, and (4) provision of good insulation during the winter (Vymazal, 2013). P. australis aboveground biomass in HF CWs varies widely between the values $<1000 \mathrm{~g} \mathrm{~m}-2$ to more than $11,000(\mathrm{~g} / \mathrm{m}-2)$ on dry matter basis and growing in natural stands also varies greatly within the similar range as in constructed wetlands (Vymazal and Březinová, 2016). As the nitrogen and phosphorus are essential elements for plants and living beings, meanwhile domestic and industrial wastewater which is not fully treated can be among the most important factors that threatens the water quality (Chang et al., 2006). There has been a growing evidence that constructed wetlands with emergent vegetation are more efficient as compared to unplanted filters and that some species are more efficient than the other ones (Zhang et al., 2010).

The objective of this study was to determine the effect of nutrient removal by Medicago sativa, Lactuca sativa, Phragmites australis and mixture of (Medicago sativa and Lactuca sativa) while they grew in municipal wastewater as the first treatment system. Also, the removal efficiency of these plants during 9 months experiments was compared.

\section{Experiment}

\section{Pilot experimental set-up}

A pilot experimental system was established in Ekbatan wastewater treatment plan and the study was carried out from April 2015 to December 2015. In Iran, the spring begin on April while the summer and autumn begin on July and October, respectively. The system was comprised of five horizontal subsurface flow CW units in parallel with a different plant species each: CW1 (unplanted), CW2 (Medicago sativa) CW3 (Lactuca sativa), CW4 (Phragmites australis) and CW5 (Mixture of Medicago sativa and Lactuca sativa) as shown in Figure 1. 


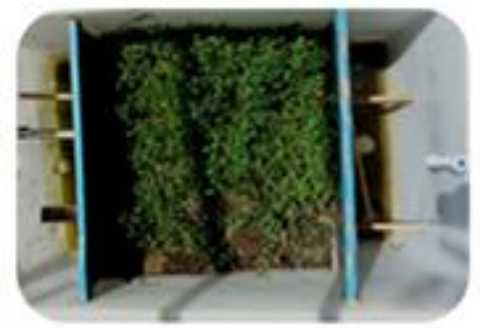

Medicago sativa

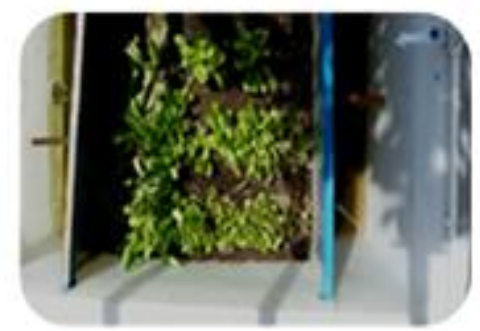

Lactuca sativa

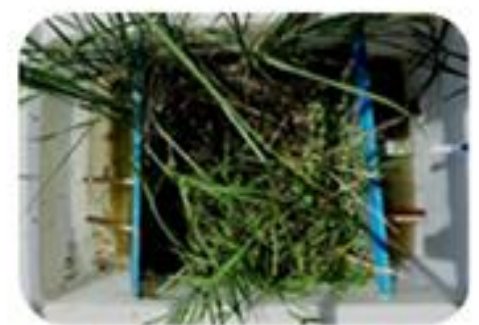

Phragmites Australis

Figure 1. Plant cultivation in separate reactors

Each CW unit has length of 1.15 , width of 0.75 and depth of 0.6 meters. Inside the reactor was completed with stones of various diameters as larger stones $(15-32 \mathrm{~mm})$ were placed at the bottom, medium $(9.5-15 \mathrm{~mm})$ and small $(6-9 \mathrm{~mm})$ placed at the middle and the top. The wastewater was entered with a flow rate of $(0.093 \mathrm{~L} / \mathrm{day})$ to the system continually. The length of $M$. sativa root was inside the sand $10 \mathrm{~cm}$ while it was $6 \mathrm{~cm}$ for L. sativa is $6 \mathrm{~cm}$ (in a radius way). In the case of $P$. australis, the bushy root reached to the bottom of the soil. The overall design of pilot study is shown in Figure 2.

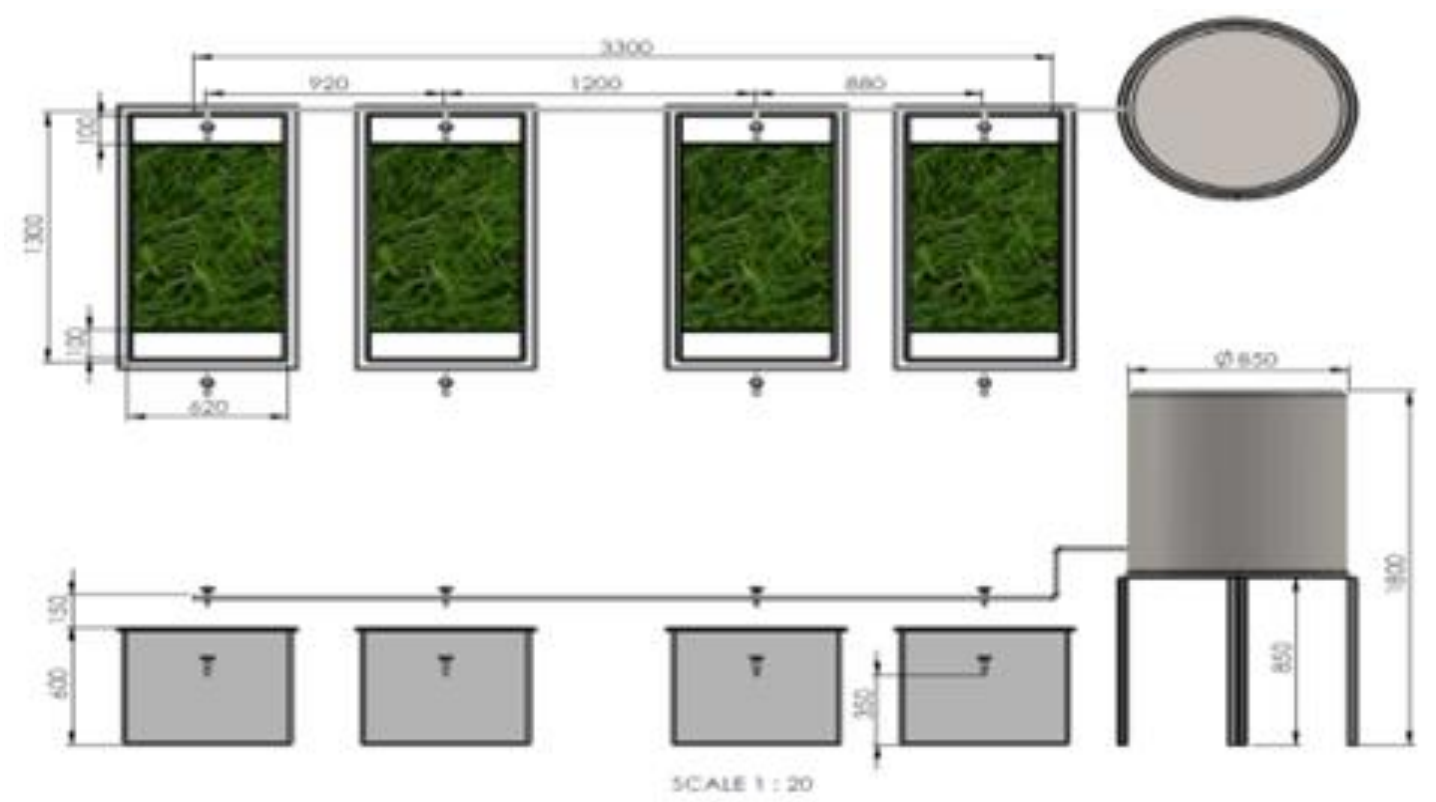

Figure 2. Design of horizontal subsurface flow constructed wetland in the study

\section{Water sampling and analysis}

The influent comes from raw wastewater as first treatment system which located at Ekbatan township in Tehran. The samples were collected from influent and effluent of each CWs daily for the analyses. The sampling last for 10 days of each month (standard deviation) and each test was conducted in triplicates. All the parameters were investigated in accordance to APHA (2005) BOD, COD and TSS were measured by 
following methods: $\mathrm{BOD}_{5}$ determined using 5-Day $\mathrm{BOD}$ test method, $\mathrm{COD}$ by colorimetric method (5220-D) and TSS by using Method No. 2540D. The total P was measured using the vanado-molybdate colorimetric method by measuring the absorbance at a wavelength of $420 \mathrm{~nm}$ (Fiske and Subbarow, 1925). Kjeldahl nitrogen was measured using APHA (2005).

\section{Results and discussion}

The removal efficiency of each plant in CWs during 9 months in different seasons was investigated and discussed as shows in Table 1.

Table 1. Removal efficiency based on different CWs

\begin{tabular}{|c|c|c|c|c|}
\hline \multirow{2}{*}{ CWs } & Plant species & \multicolumn{3}{|c|}{ Removal efficiency } \\
\cline { 3 - 5 } & & Spring & Summer & Autumn \\
\hline $\mathbf{1}$ & Medicago Sativa & low & high & moderate \\
\hline $\mathbf{2}$ & Lactuca sativa & moderate & high & moderate \\
\hline $\mathbf{3}$ & Phragmites Australis & moderate & high & moderate \\
\hline $\mathbf{4}$ & Medicago Sativa \& Lactuca sativa & moderate & high & moderate \\
\hline
\end{tabular}

\section{Medicago sativa}

As shown in Figure 3 during the first months of plant operation, COD decreased gradually which the lowest was 385 on 5 month in the summer. It showed the linear and stable reduction till end of the experiment. The reduction was around 50\% using Medicago sativa for the treatment of municipal wastewater. Similarly, BOD showed same reduction while after month $5(35 \%)$, small increases observed which may related to biomass growth and seasonal changes. In regard to nutrient removal like $\mathrm{P}$ and $\mathrm{TN}$, the reduction occurred till 4 month (summer). In summer, the amount of $\mathrm{P}$ and TN increased slightly while was fluctuated for TN. During autumn, P values in water decreased proportionally while TN showed lesser reduction rate by $25 \%$. In regard to TSS, it increased sharply till from spring till end of summer (6 months) which the highest was by $120 \%$ on 6 months. Then, it decrease during autumn till end of experiment. 

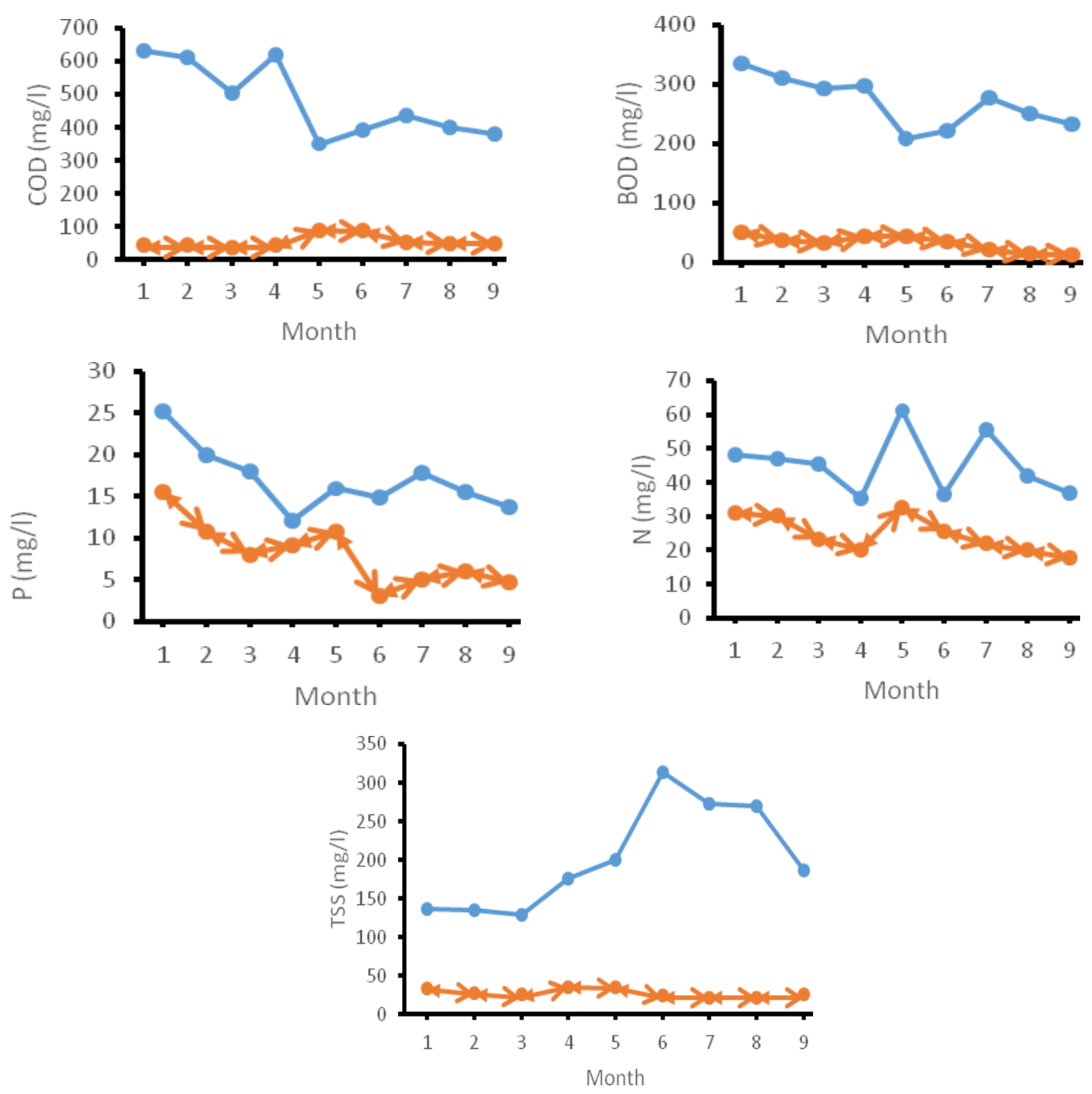

Figure 3. Nutrient removal by $M$. sativa

\section{Lactuca sativa}

There is no studies which used Lactuca sativa for wastewater treatment. This plant reduced COD by $40 \%$ during first five months of the experiment. Then, COD increased during autumn till end of the experiment. In regard to BOD, similar reduction occurred which was highest by $35 \%$ on middle of summer after 5 months of the experiment. $L$. sativa had similar removal reduction pattern for $\mathrm{T}$ and $\mathrm{TN}$ which reduced after 4 months of the experiment. The highest removal was $60 \%$ and $30 \%$ for $\mathrm{P}$ and $\mathrm{TN}$, respectively. By using Lactuca sativa, TSS was increased till end of summer by $100 \%$ and then decreased till end of autumn (Figure 4). 

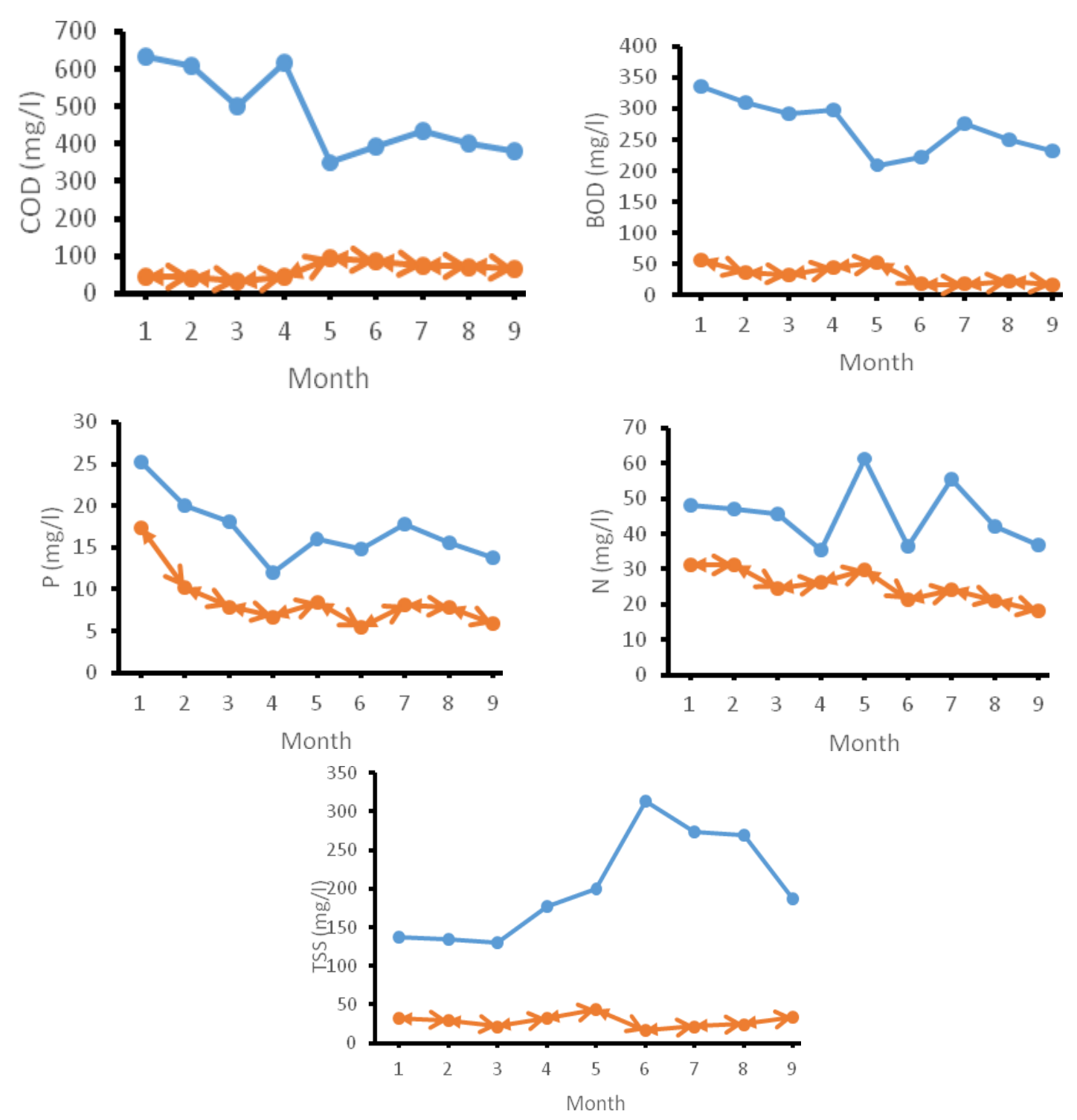

Figure 4. Nutrient removal by L. sativa

\section{Phragmites australis}

Many studies showed the efficiency of $P$. australis in removal of nutrient from different types of wastewater. This plant was effective in removal of BOD and COD over the five years (Březinová and Vymazal, 2014). Although, Carballeira et al. (2016) found that the high increases in TSS by using $P$. australis. In this study, $P$. australis removed COD and BOD by $40 \%$ and $30 \%$ till end of summer, respectively. Similarly, $\mathrm{P}$ and TN removed significantly till starting of summer by $65 \%$ and $30 \%$ respectively. Fuchs et al. (2011) found lesser removal rate of TN and P using Phragmites australis which was as $35.6 \%$ and $31 \%$ respectively. As indicated by Carballeira et al. (2016), $P$. australis had an intermediate biomass production rate and an increased nitrogen removal rate by approximately $30 \%$ in comparison with the control. As shown in Figure 5 , TSS increased till end of summer and was decreased during autumn proportionally. 

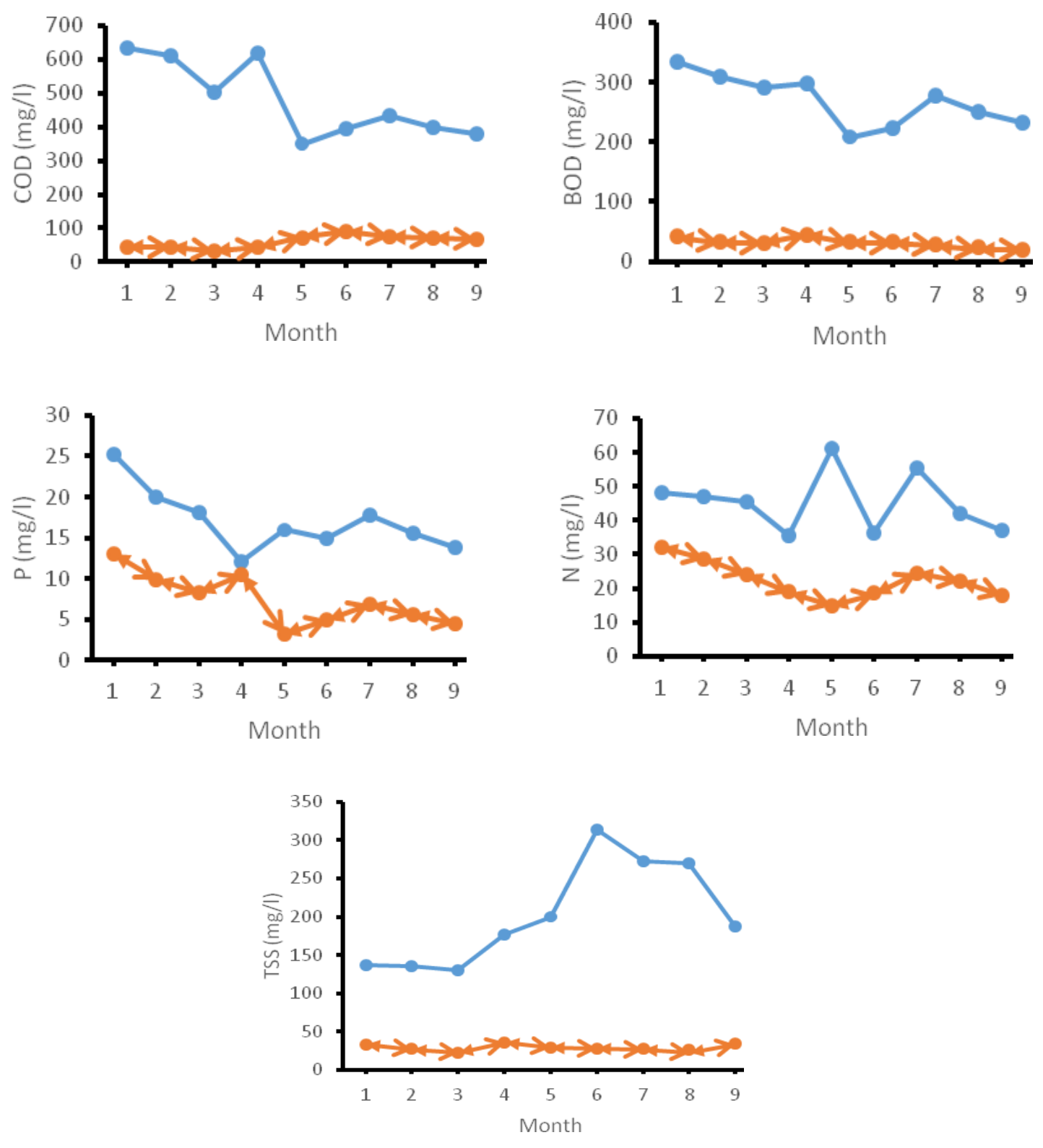

Figure 5. Nutrient removal by $P$. Australis

\section{Mix of L. sativa and M. sativa}

As shown in Figure 6, in the CWs contains mixture of L. sativa and M. sativa, similar observation of reduction was observed. The obtained results showed in was inconsistence with reduction of these plants when they culture in CWs alone. Most of the reduction occurred during summer while it was lesser during autumn. Highest removal of most of the parameters was in summer which followed by autumn and the lowest was in spring (Figure 6). It shows that the duration and season are the important factors which influenced removal efficiency. 

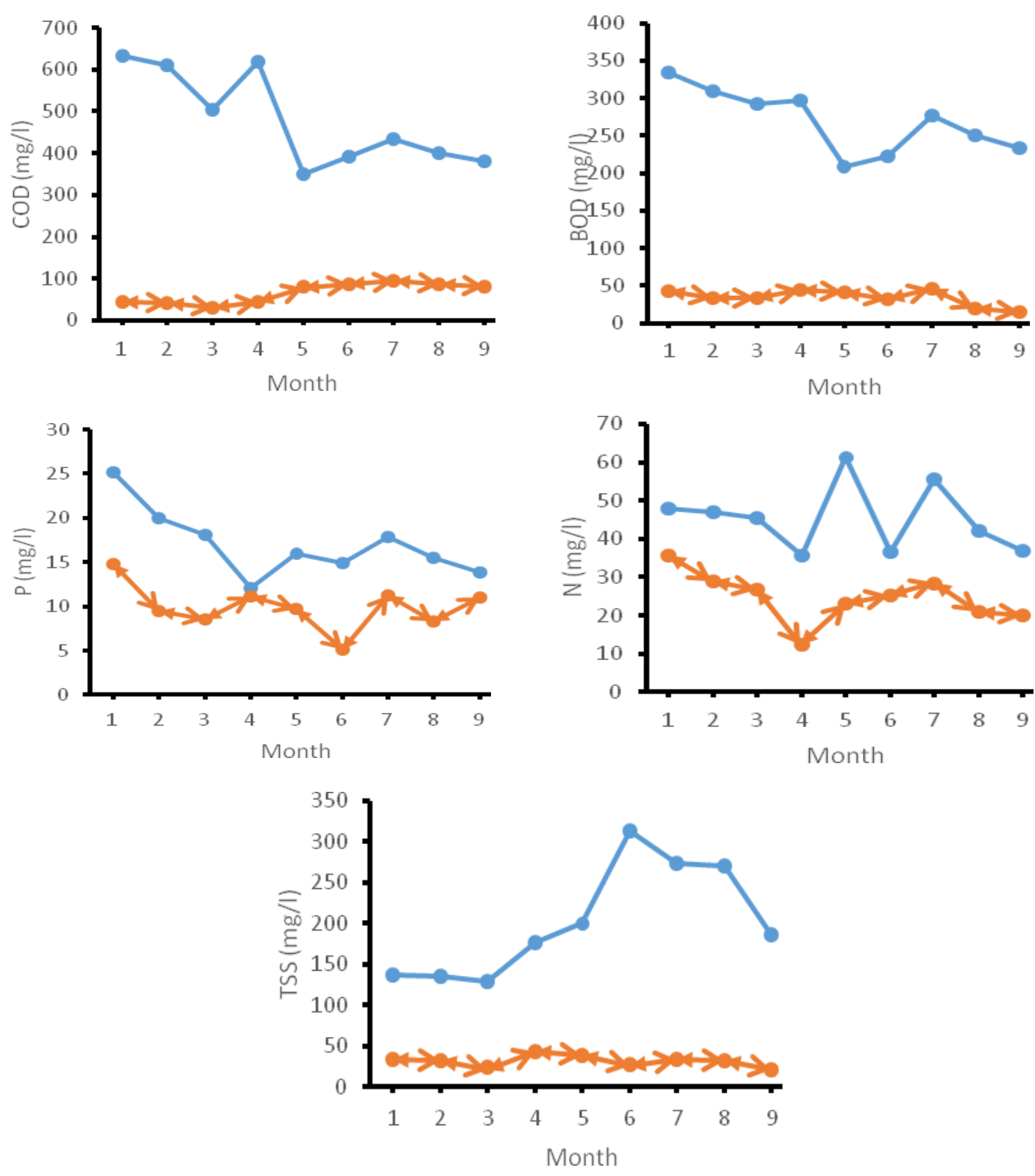

Figure 6. Nutrient removal by mix of $L$. sativa \& $M$ sativa

\section{Conclusion}

In this study, the effectiveness of nutrient removal by Medicago sativa, Lactuca sativa, Phragmites australis and mixture of (Medicago sativa and Lactuca sativa) in farictaed CWs was investigated. Different parameters like COD, BOD, TSS, P and TN measured during 9 months treatment system of municipal wastewater. Similar reduction pattern was observed during experiment while the highest reduction occurred during summer which followed by spring and autumn, respectively. In terms of removal efficiency in CWs, the highest reduction obtained using Phragmites australis which followed by (Medicago sativa and Lactuca sativa), Medicago sativa and Lactuca sativa. The average of removal rate was for COD (40-65\%), BOD (30-50\%), TSS (100-120\% increase), $\mathrm{P}(40-60 \%)$ and $\mathrm{TN}(25-35 \%)$. This study proved that the horizontal 
subsurface flow CWs are the effective method for wastewater treatment for initial and secondary treatment.

Acknowledgment. The authors would like to take this opportunity and express their gratitude to the former and current managers; Mr. Safarkhanloo, Mr. Ghasemi and Ms. Anbir and her colleagues. The sincere appreciation goes to Tehran Water and wastewater treatment and provision center for fully supporting the implementation of this study.

Conflict of Interest. The authors certify that they have NO affiliations with or involvement in any organization or entity with any financial interest.

\section{REFERENCES}

[1] APHA. (2005): Standard Methods for the Examination of Water and Wastewater (21st ed. pp.10-15). - American Public Health Association, Washington D.C.

[2] Březinová, T., Vymazal, J. (2014): Competition of Phragmites australis and Phalaris arundinacea in constructed wetlands with horizontal subsurface flow-does it affect $\mathrm{BOD}_{5}$, COD and TSS removal? - Ecological Engineering 73: 53-57.

[3] Brisson, J., Chazarenc, F. (2009): Maximizing pollutant removal in constructed wetlands: should we pay more attention to macrophyte species selection? - Science of the Total Environment 407(13): 3923-3930.

[4] Carballeira, T., Ruiz, I., Soto, M. (2016). Effect of plants and surface loading rate on the treatment efficiency of shallow subsurface constructed wetlands. - Ecological Engineering 90: 203-214.

[5] Chang, H. Q., Yang, X. E., Fang, Y. Y., Pu, P. M., Li, Z. K., Rengel, Z. (2006): In-situ nitrogen removal from the eutrophic water by microbial-plant integrated system. Journal of Zhejiang University SCIENCE B 7(7): 521-531.

[6] Chen, G. Q., Shao, L., Chen, Z. M., Li, Z., Zhang, B., Chen, H., Wu, Z. (2011): Lowcarbon assessment for ecological wastewater treatment by a constructed wetland in Beijing. - Ecological Engineering 37(4): 622-628.

[7] Engloner, A. I. (2004): Annual growth dynamics and morphological differences of reed (Phragmites australis [Cav.] Trin. ex Steudel) in relation to water supply. - FloraMorphology, Distribution, Functional Ecology of Plants 199(3): 256-262.

[8] Engloner, A. I. (2009): Structure, growth dynamics and biomass of reed (Phragmites australis)-A review. - Flora-Morphology, Distribution, Functional Ecology of Plants 204(5): 331-346.

[9] Fiske, C. H., Subbarow, Y. (1925): The colorimetric determination of phosphorus. Journal of Biological Chemistry 66(2): 375-400.

[10] Fuchs, V. J., Mihelcic, J. R., Gierke, J. S. (2011). Life cycle assessment of vertical and horizontal flow constructed wetlands for wastewater treatment considering nitrogen and carbon greenhouse gas emissions. - Water research 45(5): 2073-2081.

[11] Lissy, A. M. P. N., Madhu, B. D. G. (2010): Removal of heavy metals from waste water using water hyacinth. - ACEEE International Journal on Transportation and Urban Development 1(1): 48-52.

[12] Marchand, L., Mench, M., Jacob, D. L., Otte, M. L. (2010): Metal and metalloid removal in constructed wetlands, with emphasis on the importance of plants and standardized measurements: a review. - Environmental Pollution 158(12): 3447-3461.

[13] Pedescoll, A., Sidrach-Cardona, R., Hijosa-Valsero, M., Bécares, E. (2015): Design parameters affecting metals removal in horizontal constructed wetlands for domestic wastewater treatment. - Ecological Engineering 80: 92-99. 
[14] Qasaimeh, A., AlSharie, H., Masoud, T. (2015): A Review on Constructed Wetlands Components and Heavy Metal Removal from Wastewater. - Journal of Environmental Protection 6: 710-718.

[15] Rezania, S., Ponraj, M., Talaiekhozani, A., Mohamad, S. E., Din, M. F. M., Taib, S. M., Sairan, F. M. (2015): Perspectives of phytoremediation using water hyacinth for removal of heavy metals, organic and inorganic pollutants in wastewater. - Journal of environmental management 163: 125-133.

[16] Tanner, C. C. (2001): Plants as ecosystem engineers in subsurface-flow treatment wetlands. - Water Science and Technology 44(11-12): 9-17.

[17] Vymazal, J. (2010): Constructed wetlands for wastewater treatment: five decades of experience. - Environmental science \& technology 45(1): 61-69.

[18] Vymazal, J. (2013): Vegetation development in subsurface flow constructed wetlands in the Czech Republic. - Ecological Engineering 61: 575-581.

[19] Vymazal, J., Březinová, T. (2016): Accumulation of heavy metals in aboveground biomass of Phragmites australis in horizontal flow constructed wetlands for wastewater treatment: A review. - Chemical Engineering Journal 290: 232-242.

[20] Zhang, C. B., Wang, J., Liu, W. L., Zhu, S. X., Liu, D., Chang, S. X., Ge, Y. (2010): Effects of plant diversity on nutrient retention and enzyme activities in a full-scale constructed wetland. - Bioresource technology 101(6): 1686-1692. 